\title{
A SUBJECTIVE SENSE OF THE QUALITY OF LIFE IN ADOLESCENTS FROM THE ŚWIĘTOKRZYSKIE VOIVODSHIP
}

\section{MAŁGORZATA JASIŃSKA ${ }^{1}$, MAREK SIKORSKI ${ }^{1}$, TOMASZ WÓJCIK ${ }^{1}$, JAROSŁAW CHMIELEWSKI², MAGDALENA FLOREK-ŁUSZCZKI ${ }^{3}$, RADOSŁAW SIERPIŃSKI ${ }^{4}$, MONIKA SZPRINGER ${ }^{1}$, and GRAŻYNA NOWAK-STARZ ${ }^{1}$}

${ }^{1}$ Jan Kochanowski University in Kielce, Kielce, Poland

Faculty of Medicine and Health Sciences

${ }^{2}$ College of Rehabilitation in Warsaw, Warsaw, Poland

${ }^{3}$ Institute of Rural Health in Lublin, Lublin, Poland

Department of Medical Anthropology

${ }^{4}$ Cardinal Stefan Wyszyński University in Warsaw, Warsaw, Poland

Collegium Medicum

\begin{abstract}
Objectives: The measurement of the health-related quality of life (HRQOL) is one of the most important methods for self-assessment of health, which makes it possible to identify irregularities in the physical, mental and social functioning. The aim of the research was to determine HRQOL using the Health Related Quality of Life Questionnaire for Children and Young People (the KIDSCREEN-52 questionnaire) - the instrument recommended by the World Health Organization - which makes it possible to distinguish groups of adolescents with a diversified subjective sense of the quality of life. Material and Methods: The study involved a group of 871 adolescents, 411 boys and 460 girls, aged 13-16 years, residing in the Świętokrzyskie Voivodship. The method of a diagnostic survey was used in the research. The KIDSCREEN-52 questionnaire, which is an instrument for examining the HRQOL of adolescents, was employed in the study. The k-means clustering method was applied, which made it possible to establish 3 groups of adolescents with a different subjective sense of the quality of life. Results: Three groups of adolescents with a diversified subjective sense of the quality of life (high, average, low) were identified using the KIDSCREEN-52 questionnaire. The subjective quality of life in the majority of the respondents was high, in particular in those living in rural areas. The surveyed boys with a high subjective quality of life showed a significantly higher self-esteem, acceptance and peer support than the surveyed girls. Conclusions: The KIDSCREEN-52 questionnaire is an accurate and sensitive tool for assessing HRQOL. It allows identifying 3 groups of adolescents with a diversified subjective sense of the quality of life. It can form the basis for further diagnosis of the bio-psycho-social functioning of adolescents. Int J Occup Med Environ Health. 2021;34(3):415-25
\end{abstract}

Key words:

self-assessment, adolescents, quality of live, KIDSCREEN-52 questionnaire, Świętokrzyskie Voivodship, diagnostic survey

Funding: this work was supported by the Ministry of Science and Higher Education (project No. 024/RID/2018/19 entitled "Regional Initiative Excellence in 2019-2022").

Received: August 2, 2020. Accepted: October 28, 2020.

Corresponding author: Magdalena Florek-Łuszczki, Institute of Rural Health in Lublin, Department of Medical Anthropology, Jaczewskiego 2, 20-950 Lublin, Poland (e-mail: magdalena.florek@wp.pl). 


\section{INTRODUCTION}

According to the modern definition provided by the World Health Organization (WHO), health is considered not only as a total absence of disease or disability, but also as a state of full physical, mental and social well-being, manifested in all spheres of activity in human life [1]. The WHO definition, therefore, emphasizes the aspect of a multi-dimensional and subjective nature of health [2]. In contemporary research on the health of children, adolescents and adults, attention is focused on the use of subjective measures, i.e., self-assessment of health. This measurement is carried out by the respondents themselves, and not by professionals, as is the case with objective health assessment. Attempts are being made to use various tools to assess subjective health [3].

The measurement of the health-related quality of life (HRQOL) is currently one of the most important methods of self-assessment of health, which makes it possible to detect abnormalities in the physical, psychological and social functioning [4]. It is especially significant for the period of adolescence and the so-called young adults, where negative health indicators are definitely lower than in the adult population.

Measurement is the process of assigning numbers to objects or events according to certain rules, as a result of which the concepts and empirical indicators visible in the responses are combined. Therefore, in order to record data [5], research tools are created and developed. Due to a variety of definitions, many measurement tools have been developed to assess the quality of life. The most commonly used are questionnaires, and the quality of life scales and indexes. The decisive indicator for the assessment of the quality of life is the assessment of the subjective perception of the life situation, conditioned by the state of health from the respondent's point of view. It is in the sphere of his/her experience, so it is a subjective phenomenon, e.g., what is positively perceived by one person may be negatively perceived by someone else [6-8].
One of the commonly used methods is a multivariate test that enables an in-depth assessment of the patient's well-being. It is qualitative in nature and very laborious. Another method of assessing the quality of life is a questionnaire study, which allows for quantitative results to be obtained $[6,9]$.

The quality of life questionnaires are divided into: general, specific and mixed. General questionnaires allow assessing the overall quality of life in the basic areas of functioning; they are used to assess the relationship between the patient's health condition and factors such as family relationships, professional activity, and emotional state. General questionnaires are employed in large studies and for both healthy and sick populations. They are universal and their results can be compared between different populations. In addition, general questionnaires are recommended especially for screening the whole population in Poland. Examples of general questionnaires are: the WHO Quality of Life-BREF (WHOQOL-BREF), the Short Form Health Survey (SF-36), the Sickness Impact Profile, and the Quality of Life Index [9-11].

Specific questionnaires are further divided into 2 categories. The first category analyzes some specific spheres of the patient's functioning, while the second one analyzes factors that result from the disease itself, refer to a specific disease (e.g., asthma, diabetes) or a group of diseases (e.g., diseases of the cardiovascular system), and may also be addressed to a specific population under the study (e.g., children, adolescents, the elderly), as well as to social functions, self-esteem or body image [10].

The second category enables the assessment of factors such as the patient's well-being, the impact of the disease on his/her emotional state, the severity of symptoms, and everyday social and professional activity [12]. Examples of specific questionnaires are: the Pairs Questionnaire for Dialysis Patients, the Quality of Life Scale (QLS-100) used in psychiatric disorders, the Quality of Life Questionnaire (QLO-C30) used in cancer patients, the Asthma 
Quality of Life Questionnaire (AQLO), and the St. George's Respiratory Questionnaire (SGRO) [13,14].

Mixed questionnaires include both, general and specific questionnaires.

The quality of human life is an extremely subjective value and it depends, to a large extent, on the mental state, preferences, personality traits, value systems, etc. [15].

The assessment of HRQOL in children and adolescents in European countries and in the USA became popular in the 1980s and 1990s. Since then, new tools for measuring the quality of life in children and adolescents have been developed, taking into account the specificity of developmental age, and comprehending the issues of development and health in terms of the quality of life. Reports on the quality of life of children and adolescents enable the detection of disorders, defects and abnormalities by promoting and monitoring physical development, and by assessing the quality of life and treatment. The problem of the quality of life and its measurement has become one of the crucial issues in pediatric practice [16].

One of the most frequently used tools for studying the quality of life in pediatric and adolescent populations is the Pediatric Quality of Life (PedsQL) questionnaire, which facilitates monitoring the health condition and measuring treatment effects. This questionnaire is a reliable measuring tool, used in examining healthy and chronically ill children and adolescents [17]. The author of the PedsQL questionnaire also used the assessment of the quality of life of the surveyed children and adolescents, carried out by their legal guardians.

The PedsQL questionnaire consists of 2 versions: general and supplementary. The supplementary version assesses some characteristic symptoms and modes of treatment. Version 4.0 of the PedsQL questionnaire is used to test and compare healthy children and children with acute and chronic health problems. The questionnaire allows for measurements of various spheres and takes into account the functioning in the physical, mental, social, as well as school domains [18-20].

Other tools used to assess the quality of life in chronically ill children are: the Child Health Questionnaire, the Pediatric Oncology Quality of Life Scale which is used to assess the quality of life in children with cancer [21], and AQLO which is used to assess the course and effectiveness of asthma treatment [22]. The questionnaire containing the basic dimensions of the quality of life: physical, psychological, social and environmental, as mentioned by WHO, is the Health Related Quality of Life Questionnaire for Children and Young People (the KIDSCREEN-52 questionnaire).

The KIDSCREEN-52 questionnaire is the outcome of the research project entitled: "Screening and Promotion for Health-related Quality of Life in Children and Adolescents - A European Public Health Perspective," which was carried out in 13 European countries, including Poland. The choice of this tool was closely related with the aim of the research, the study group, the possibility of cooperation with adolescents, and good psychometric properties [2,3]. The aim of the research was to determine the use of the KIDSCREEN-52 questionnaire [23], as an accurate instrument for assessing HRQOL, which makes it possible to distinguish groups of adolescents with a diversified subjective sense of the quality of life.

\section{MATERIAL AND METHODS}

On the basis of the data from the Board of Education, a list of schools located in the Świętokrzyskie Voivodship was compiled with the approval of the Bioethics Commission of the Jan Kochanowski University in Kielce (No. 04/2009). Three schools were randomly selected, 42 classes in succession, 14 classes from each school. The permission to conduct the study was obtained from the head teachers, pupils and parents.

The method of a diagnostic survey was applied to the research. It was conducted by employing the questionnaire technique. The standardized KIDSCREEN-52 ques- 
tionnaire was used in the study, developed by the KIDSCREEN Group Europe [23]. The researchers used the Polish version of the KIDSCREEN-52 questionnaire adapted by Mazur et al. [24].

The adolescents responded from the perspective of the past week. The raw results were standardized on a scale of 0-100 pts, which made it possible to obtain average indicators of the HRQOL of adolescents according to the summary scale. As a result, the natural differences between individual HRQOL dimensions were maintained [23,24]. The k-means clustering method was applied, through which 3 groups of adolescents with a diversified subjective sense of the quality of life were identified. The following statistical methods were used: arithmetic means, statistical deviations, minimum values, maximum values and medians. The assumed significance level was $p<0.05$. All the calculations were performed using the Statistica 10 v. PL package.

\section{RESULTS}

The study involved a group of 871 young people, 411 boys (47.19\%) and 460 girls (52.81\%), aged 13-16 years and residing in the Świętokrzyskie Voivodship. Pupils from 3 schools in the Świętokrzyskie Voivodship were qualified for the study as a randomly selected research sample (Table 1).

The study involved the assessment of the relationship between the selected demographic characteristics (gender, age and the place of residence) and 10 dimensions of the quality of life based on the KIDSCREEN-52 questionnaire (physical health, mental well-being, moods and emotions, self-perception, autonomy, relationship with parents, financial resources, social support, school environment, and social acceptance).

Both the boys $(90.24 \pm 15.69 \mathrm{pts})$ and the girls (91.45 $\pm 14.85 \mathrm{pts})$ showed the highest assessment of the subjective sense of HRQOL in the social acceptance dimension, which suggests that the subjective sense of the quality of life in this dimension had a major impact on both groups. The school environment dimension, indic- ating that the subjective sense of the quality of life of the boys ( $66.42 \pm 14.88 \mathrm{pts})$ and the girls (66.02 $\pm 14.86 \mathrm{pts})$ was influenced by this dimension, was much worse. The young people were dissatisfied with their school, negatively evaluating both the school itself and teachers.

The social acceptance dimension had the greatest impact on the assessment of the subjective sense of the quality of life in all age groups (the students aged 13 years: $89.72 \pm 16.25$ pts; 14 years: $91.32 \pm 14.34$ pts; 15 years: $91.57 \pm 15.06 \mathrm{pts}$; and 16 years: $90.12 \pm 16.03 \mathrm{pts}$ ), and the school environment dimension had the lowest impact (the students aged 13 years: $64.61 \pm 16.60$ pts; 14 years: $67.04 \pm 14$ pts; 15 years: $66.03 \pm 14.48$ pts; and 16 years: $66.69 \pm 14.57 \mathrm{pts})$.

As before, the social acceptance dimension had the greatest impact on the subjective sense of the quality of life in terms of the place of residence: (living in an urban area: $90.62 \pm 15.43 \mathrm{pts}$, and in a rural area: $91.04 \pm 15.16 \mathrm{pts}$ ), and the school environment dimension had the lowest impact (living in an urban area: $65.17 \pm 14.91 \mathrm{pts}$, and in a rural area: $66.87 \pm 15.16 \mathrm{pts}$ ).

During the analysis of the research regarding the impact of gender, age and the place of residence on the subjective sense of the quality of life of adolescents from the Świętokrzyskie Voivodship, it was found that there was no significant relationship with the individual dimensions of the subjective quality of life measured by the KIDSCREEN-52 questionnaire $(\mathrm{p}>0.05)$.

Descriptive statistics of the respondents (arithmetic means, standard deviation, minimum values, maximum values and medians) were calculated on the basis of the quality of life dimensions of the KIDSCREEN-52 questionnaire (Table 2).

As it was mentioned in the Material and Methods section, 3 groups of respondents with a different subjective sense of the quality of life were identified. According to the recommendations, the HRQOL indices were determined for each person participating in the study [23]. 
Table 1. Characteristics of the respondents from the Świętokrzyskie Voivodship, Poland, in the study on the health-related quality of life

\begin{tabular}{|c|c|c|c|c|c|c|}
\hline \multirow{3}{*}{ Age } & \multicolumn{6}{|c|}{$\begin{array}{c}\text { Participants } \\
(\mathrm{N}=871) \\
{[\mathrm{n}(\%)]}\end{array}$} \\
\hline & \multicolumn{3}{|c|}{$\begin{array}{c}\text { boys } \\
(\mathrm{N}=411,47.19 \%)\end{array}$} & \multicolumn{3}{|c|}{$\begin{array}{c}\text { girls } \\
(\mathrm{N}=460,52.81 \%)\end{array}$} \\
\hline & $\begin{array}{c}\text { urban areas } \\
(\mathrm{N}=165,18.94 \%)\end{array}$ & $\begin{array}{c}\text { rural areas } \\
(\mathrm{N}=246,28.25 \%)\end{array}$ & $\begin{array}{c}\text { total } \\
(\mathrm{N}=411,47.19 \%)\end{array}$ & $\begin{array}{c}\text { urban areas } \\
(\mathrm{N}=175,20.09 \%)\end{array}$ & $\begin{array}{c}\text { rural areas } \\
(\mathrm{N}=285,32.72 \%)\end{array}$ & $\begin{array}{c}\text { total } \\
(\mathrm{N}=460,52.81 \%)\end{array}$ \\
\hline 13 years & $19(11.52)$ & $56(22.76)$ & 75 (8.61) & $28(16.00)$ & $54(18.95)$ & 82 (9.41.) \\
\hline 14 years & $55(33.33)$ & $64(26.02)$ & $11(13.66)$ & $50(28.57)$ & $96(33.68)$ & $146(16.76)$ \\
\hline 15 years & $57(34.55)$ & $72(29.27)$ & $129(14.81)$ & $59(33.71)$ & $89(31.23)$ & 148 (16.99) \\
\hline 16 years & $34(20.61)$ & $54(21.95)$ & $88(10.10)$ & $38(21.71)$ & $46(16.14)$ & $84(9.64)$ \\
\hline
\end{tabular}

Table 2. Descriptive statistics of the results for individual dimensions of the KIDSCREEN-52 questionnaire of the examined boys and girls from the Świętokrzyskie Voivodship, Poland, in the study on the health-related quality of life

\begin{tabular}{|c|c|c|c|c|c|c|c|c|c|c|}
\hline \multirow{3}{*}{ Dimensions } & \multicolumn{10}{|c|}{$\begin{array}{c}\text { Participants } \\
(\mathrm{N}=871)\end{array}$} \\
\hline & \multicolumn{5}{|c|}{$\begin{array}{c}\text { boys } \\
(\mathrm{N}=411)\end{array}$} & \multicolumn{5}{|c|}{$\begin{array}{c}\text { girls } \\
(\mathrm{N}=460)\end{array}$} \\
\hline & $\mathrm{M}$ & SD & $\min$. & $\max$ & $\mathrm{Me}$ & $\mathrm{M}$ & SD & $\min$. & $\max$ & $\mathrm{Me}$ \\
\hline Physical health & 73.26 & 14.26 & 36.00 & 100.00 & 72.00 & 72.73 & 14.47 & 36.00 & 100.00 & 74.00 \\
\hline Mental well-being & 74.88 & 15.09 & 23.33 & 100.00 & 76.67 & 75.12 & 16.50 & 20.00 & 100.00 & 80.00 \\
\hline Moods and emotions & 82.06 & 13.83 & 25.71 & 100.00 & 85.71 & 81.72 & 13.70 & 22.86 & 100.00 & 82.86 \\
\hline Self-perception & 74.11 & 15.31 & 24.00 & 100.00 & 72.00 & 72.16 & 16.14 & 20.00 & 100.00 & 72.00 \\
\hline Autonomy & 71.38 & 17.33 & 20.00 & 100.00 & 72.00 & 73.00 & 18.71 & 20.00 & 188.00 & 76.00 \\
\hline Relationship with parents & 78.75 & 17.53 & 20.00 & 100.00 & 80.00 & 80.50 & 16.66 & 20.00 & 100.00 & 83.33 \\
\hline Financial resources & 70.32 & 20.24 & 20.00 & 100.00 & 73.33 & 71.51 & 20.52 & 20.00 & 100.00 & 73.33 \\
\hline Social support & 73.88 & 16.27 & 20.00 & 100.00 & 76.67 & 73.60 & 17.67 & 20.00 & 100.00 & 76.67 \\
\hline School environment & 66.44 & 14.89 & 20.00 & 100.00 & 66.67 & 66.09 & 14.93 & 20.00 & 100.00 & 66.67 \\
\hline Social acceptance & 90.24 & 15.69 & 20.00 & 100.00 & 100.00 & 91.319 & 15.08 & 20.00 & 100.00 & 100.00 \\
\hline
\end{tabular}

On the basis of the KIDSCREEN-52 questionnaire [25], the following values were calculated: arithmetic means (the average values of HRQOL indices according to the summary scale of 0-100 pts) and standard deviations (Table 2). The analysis of the average values of HRQOL indices shows that group I is marked by the highest values, group II by the average values, and group III by the lowest values, of the quality of life indices (Table 3 ).
It was found that group I (338 people - 43.97\%) was characterized by a high subjective sense of the quality of life, group II (399 people - $38.92 \%$ of the respondents) by an average subjective sense of the quality of life, and group III (149 people $-17.11 \%$ of the respondents) by a low subjective sense of the quality of life.

The respondents from group I gave the highest rating to all dimensions of the quality of life of the KIDSCREEN-52 
Table 3. Identified groups of respondents from the Świętokrzyskie Voivodship, Poland, with a different subjective sense of the quality of life

\begin{tabular}{|c|c|c|c|}
\hline \multirow[t]{2}{*}{ Life quality dimension } & \multicolumn{3}{|c|}{$\begin{array}{c}\text { Participants } \\
(\mathrm{N}=871) \\
(\mathrm{M} \pm \mathrm{SD})\end{array}$} \\
\hline & $\begin{array}{c}\text { group I } \\
(\mathrm{N}=338)\end{array}$ & $\begin{array}{l}\text { group II } \\
(\mathrm{N}=399)\end{array}$ & $\begin{array}{l}\text { group III } \\
(\mathrm{N}=149)\end{array}$ \\
\hline W1. Physical health & $80.74 \pm 12.30$ & $70.37 \pm 12.32$ & $61.96 \pm 14.10$ \\
\hline W2. Mental well-being & $84.13 \pm 11.76$ & $73.12 \pm 12.65$ & $59.06 \pm 17.06$ \\
\hline W3. Moods and emotions & $88.55 \pm 10.06$ & $80.99 \pm 11.35$ & $69.09 \pm 16.75$ \\
\hline W4. Self-perception & $80.28 \pm 15.07$ & $72.01 \pm 13.18$ & $59.44 \pm 13.70$ \\
\hline W5. Autonomy & $84.05 \pm 12.88$ & $69.54 \pm 13.49$ & $51.81 \pm 15.10$ \\
\hline W6. Relationship with parents & $92.01 \pm 8.16$ & $78.63 \pm 11.17$ & $54.30 \pm 15.55$ \\
\hline W7. Financial resources & $85.64 \pm 12.80$ & $67.98 \pm 15.50$ & $45.46 \pm 16.15$ \\
\hline W8. Social support & $85.57 \pm 10.99$ & $70.63 \pm 12.81$ & $54.63 \pm 16.96$ \\
\hline W9. School environment & $74.27 \pm 13.37$ & $64.00 \pm 11.86$ & $53.56 \pm 14.29$ \\
\hline W10. Social acceptance & $93.86 \pm 15.05$ & $91.19 \pm 13.17$ & $83.27 \pm 18.00$ \\
\hline
\end{tabular}

Group I - with a high subjective sense of the quality of life; group II - with an average subjective sense of the quality of life; group III - with a low subjective sense of the quality of life.

questionnaire. In addition to the social acceptance dimension, their assessments were also high in the following dimensions: relationship with parents, as well as moods and emotions. The school environment dimension was given the lowest rating in group I.

The adolescents from group II gave the highest ratings, apart from the social acceptance dimension, to the following dimensions: moods and emotions, and relationship with parents, and the school environment was the lowest assessed dimension. The respondents from group III, apart from the social acceptance dimension, gave the highest ratings to the following dimensions: moods and emotions, physical health, mental well-being, and self-perception, and the lowest to autonomy and financial resources.

The analysis of the differences in the groups in the subjective sense of the quality of life, in terms of the respondents' gender, confirms the observed tendency that the perception of a higher quality of life was presented by the respondents from group I (43.97\%), followed by those from group II (38.92\%), and only then by group III (17.11\%), but these differences were not significant ( $p>0.05)$.

When examining the impact of age on the assessment of the subjective sense of the quality of life related to health, a difference was found between the respondents aged 13 years $(18.03 \%)$ with a gradual increase in differences in the subsequent age groups, i.e., among those aged 14 years (30.42\%) and 15 years $(1.80 \%)$.

The results of the analysis indicate no significant differences between the 3 groups distinguished in terms of the subjective sense of the quality of life and the respondents' age $(p>0.05)$ or place of residence $(p>0.05)$.

\section{DISCUSSION}

The majority of WHO researchers define health as a complete biological, mental and social well-being, and the quality of life as physical, emotional and social aspects of the patient's well-being [26].

According to modern definitions, health has many dimensions including the physical, mental and social functioning. 
However, spiritual health is yet another dimension, which is related to the system of human values [27]. The quality of life is a subjective value, conditioned by the mental state, preferences, personality traits and the acknowledged system of values [9], and it should not be treated as an objectively observed set of indicators. On the other hand, subjective measures reflect mental well-being, satisfaction and happiness [28].

According to Nutbaem's approach [29], objective health indicators are increasingly supplemented by subjective ones, i.e., the subjective feeling of satisfaction and wellbeing, as well as by elements of health policy.

The concept of HRQOL is based on the multi-dimensional concept of health. Agathão et al. [30], in a crosssectional study involving 807 teenage students from 4 private schools in Rio de Janeiro and São Gonçalo, and from 2 schools belonging to the public Niterói network, proved that the perception of the quality of life in adolescents, obtained with the KIDSCREEN-27 questionnaire was satisfactory, and lower values concerned only the following dimensions: autonomy and relations with parents. As compared to the results of the European KIDSCREEN study from different countries, it can be generally noticed that the surveyed youth perceived their HRQOL more positively, although their living conditions were lower than in the case of European youth [23,30].

According to Oleś [31], studies on the quality of life of children and adolescents pose a special challenge to researchers. This is caused by the change dynamics and its specificity, which are characteristic of the adolescence period, and the developing process of both teenagers' personality and self-assessment abilities.

Bańka [32] indicated that the quality of life was related to the quality of development, i.e., the criteria for assessing the quality of life are a derivative of the needs that result from development, i.e., from the need of belonging and autonomy. The way of shaping the identity was also considered important.
Adolescence is considered as a critical period because of the increased risk of psychiatric disorders as well as the development and fixation of health behaviors, both favorable and unfavorable. Therefore, special attention should be paid to proper investments in the health of adolescents, which would determine the further functioning of society, both now and from the perspective of several decades [27,33].

In 2018, the Health Behavior in School-aged Children (HBSC) report was published as part of international research into health behavior of school children. The new model of HBSC, which combines 4 main perspectives: psycho-social population, macro-social and developmental, emphasizes the areas of biological development and maturation. Currently, HBSC studies influence the formation of models describing the factors that support the development of adolescents. The new integrated and multidimensional HBSC research model makes it possible to use its results for the following purposes:

- describing the health self-assessment and health behavior of adolescents in a social context;

- searching for protective and risk factors of health and health behaviors of adolescents;

- describing and analyzing various areas of the functioning of adolescents;

- performing an analysis at the individual level and at the level of a school class, a school or the whole country;

- analyzing trends of changes in individual health areas;

- making international comparisons;

- participating in the evaluation of preventive and intervention programs at the local or national level [34].

Cross-sectional studies by Gil-Lacruz et al. [34], conducted in the Casablanca District of Zaragoza (Spain), were particularly important for young people, as understanding the interaction between health and education facilitated the design of a preventive policy influencing their HRQOL. The WHOQOL-BREF which was used to this 
end contained the following dimensions: mental well-being, physical health, social relations and the environment. The mental well-being dimension had the greatest impact on education, but this impact was modulated by gender and the place of residence [34]. The concept of the quality of life and health education integrates the bio-psychosocial perspective of health and the multi-dimensional potential of education for well-being.

The KIDSCREEN-52 questionnaire used in the study made it possible to assess health in the following $10 \mathrm{HRQOL}$ categories: physical health, mental well-being, moods and emotions, self-perception, relationship with parents, social support, autonomy, school environment, financial resources and social acceptance [25].

The research material involved 871 pupils aged 13-16 years, including 411 (47.19\%) boys and $460(52.81 \%)$ girls. The results presented in the paper constitute a small part of the extensive cross-sectional research on the development and health of adolescents from the Świętokrzyskie Voivodship, conditioned by the subjective and objective sense of the quality of life.

The impact of gender, age and the place of residence on the subjective sense of the quality of life of adolescents was determined in the first part of the analysis of the research results concerning a group of adolescents. The social acceptance dimension was the strongest facet of the respondents in terms of gender, age and the place of residence, whereas the school environment dimension was the weakest. When assessing the impact of the above mentioned factors on the overall subjective sense of the quality of life of the respondents, no significant relationship was found for any of the $10 \mathrm{HRQOL}$ dimensions $(\mathrm{p}>0.05)$.

The same as in the authors' research, the social acceptance dimension was also given the highest score in the Polish nationwide research dated 2003, and in the research on adolescents from the Świętokrzyskie Voivodship conducted by Krawczyńska et al. [35], and Zięba et al. [36].
The social acceptance dimension provided evidence that the respondents were accepted by their peers, and that they did not experience any distress (bullying) on their part. The school environment dimension had the lowest score, which shows that some of the adolescents were dissatisfied with their school; their evaluation of both the school itself and their teachers was poor.

According to Krawczyńska et al. [35], "A better assessment of HRQOL is conditioned by making conscious, responsible decisions with reference to personal health and beliefs, and that good health is conditioned by taking pro-health actions."

Thus, it is very important how health is perceived, especially during adolescence, and how it is rated in comparison to other values.

Due to the use of appropriate research instruments, the study confirmed that it is possible to assess the health condition of adolescents by determining their physical, mental and social well-being. The reason for the lower scores in the assessment of the quality of life among the surveyed girls, as compared to the boys, is the fact that girls generally care more about their own health than boys, and because they are more sensitive, they are more susceptible to psychosomatic and mental disorders [35]. In the study of children and adolescents aged 8-18 years, Mazur et al. [24] proved that the respondents gave the lowest rating to dimensions relating to social functioning, including financial resources, the family material condition and the school environment.

The Spanish National Health Survey is a series of studies that have been the main source of information on the perceived health of the population living in Spain. Gallego-Méndez et al. [37] assessed the relationship between HRQOL using the National Health Survey of Spain (Encuesta Nacional de Salud de España 2017 - ENSE 2017) questionnaire and the frequency of physical activity in Spanish children aged 8-14 years with attention deficit hyperactivity disorder (ADHD). They showed significant differences between different levels of physical activity frequency, as well 
as positive correlations of the mean between HRQOL and ADHD. The results of such analyses confirmed that physical activity can contribute to the improvement of HRQOL in children with ADHD.

Oleś [31] claimed that "it is necessary to assess the quality of life in the developmental period in the overall treatment program, this is also important from the point of view of preventing the psycho-social effects of the disease and promoting health.”

The results of the analyses supported the hypothesis about the possibility of developing a methodology for determining groups of adolescents with a different subjective sense of the quality of life. They were performed taking into account standards relating to Polish nationwide studies conducted in 2003 by the Institute of Mother and Child in Warsaw, in the light of research with the application of the KIDSCREEN-52 questionnaire [23].

When analyzing the average HRQOL values, it was found that the adolescents from group I gave the highest scores to the 10 dimensions of the quality of life. In addition to the social acceptance dimension, they also gave high scores to their relationships with parents, and moods and emotions. These respondents were accepted by their peers, and did not experience any distress on their part. They felt loved, supported and understood by their parents. They were feeling well and emotionally balanced. The school environment was the lowest assessed dimension, which is reflected by the fact that the students did not always perceive school as a friendly place, at the same time showing a lack of satisfaction from their learning achievements [25].

In addition to the social acceptance dimension, adolescents from group II gave the highest scores to the moods and emotions, and relationship with parents dimensions, and the lowest to the school environment dimension. The respondents were accepted by their peers, did not experience bullying or teasing, and felt well and were emotionally balanced. They also felt treated fairly by their par- ents, loved, supported and understood, but they did not always perceive school as a friendly place [25].

The students from group III, apart from the social acceptance dimension, gave the highest scores to the moods and emotions, physical health, mental well-being, and self-perception dimensions. The adolescents from this group did not always feel accepted by their peers, sometimes were bullied, and sometimes experienced loneliness, sadness and resignation.

They did not always feel healthy, active, fit and full of energy. The adolescents were rather self-confident, but not always satisfied with their appearance, and they neither cared much about their appearance nor showed any willingness to change [25]. The respondents from group III gave the lowest scores to the autonomy and financial resources dimensions. The adolescents from this group were not always satisfied with their family's financial resources which would allow them to lead a peer-like life style, as the feeling of financial constraints influenced the possibility of buying certain goods or having access to entertainment [23]. Undoubtedly, the completed studies have a cognitive value, as they extend the knowledge on the subjective sense of the quality of life and its determinants in adolescents from the Świętokrzyskie Voivodship.

\section{CONCLUSIONS}

The KIDSCREEN-52 questionnaire is an accurate instrument for assessing HRQOL, which makes it possible to identify groups of adolescents with a diverse subjective sense of the quality of life (high, average and low), which can then form the basis for further diagnosis of the biopsycho-social functioning of young people.

The subjective assessment of the quality of life in the majority of the respondents was high, especially among those living in the countryside.

The boys with a high subjective sense of the quality of life showed a significantly higher sense of self-esteem, acceptance and peer support than the girls. 


\section{REFERENCES}

1. Sygit M. [Public Health]. Warszawa: Wolters Kluwer Publishing; 2010. Polish.

2. Heszen I, Sęk H. [Behavioral determinants of health and disease]. In: Heszen I, Sęk H, editors. [Health psychology]. Warszawa: PWN Scientific Publisher; 2012. p. 90-104. Polish.

3. Nowak-Starz G, Zięba E. Lifestyle related to health and quality of life of girls at puberty in light of the KIDSCREEN-52 Questionnaire. Med Stud. 2017;33:117-26, https://doi.org/10.5114/ms.2017.68705.

4. Krawczyńska J, Łukawska P. Health-related quality of life of adolescents in the context of selected somatic development indices. Med Stud. 2016;32:189-95, https://doi.org/10.5114/ ms.2016.62310

5. Przybyszewski B, Czerwionka-Szaflarska M, ŻbikowskaBojko M. [Analysis of the quality of life of children and adolescents with type 1 diabetes treated with continuous subcutaneous insulin infusion]. Pediatr Pol. 2008;83:54-62, https:// doi.org/10.1016/S0031-3939(08)70290-7. Polish.

6. Kowalik S. [Usefulness of the quality of life concept for the rehabilitation of disabled people]. In: Wołowicka L, editor. [Quality of life in medical science]. Poznań: Wydawnictwo Akademii Medycznej im. K. Marcinkowskiego w Poznaniu; 2001. p. 54-71. Polish.

7. Jaeschke R, Guyatt G, Cook D, Miller J. [Identifying and measuring quality of life related to health]. Med Prakt. 1999;4:77-82. Polish.

8. Heszen I, Sęk H. [Health psychology]. Warszawa: Wydawnictwo Naukowe PWN; 2007. p. 56-9, 166-71. Polish.

9. De Walden-Gałuszko K. [Assessment of health-related quality of life]. In: Meyza J, editor. [Quality of life in neoplastic disease]. Warszawa: Centrum Onkologii Instytutu im. Marii Skłodowskiej-Curie; 1997. p. 77-85. Polish.

10. Kochman D, Szafarska M. [Analysis of the quality of life of children and adolescents with simple obesity]. Pediatr Pol. 2004;79:49-56. Polish.

11. Wołowicka L, Jaracz K. [Polish version of WHOQOLWHOQOL 100 and WHOQOL-Bref]. In: Wołowicka L, editor. [Quality of life in medical science]. Poznań: Wydawnictwo Akademii Medycznej im. K. Marcinkowskiego w Poznaniu; 2001. p. 235-65, 291-301. Polish.

12. Ware J, Brook R, Devies-Avery A. SF-36 Health Survey: manual and interpretation guide. Boston, MA: The Health Institute, New England Medical Center; 1993.

13. Bowling A. Measuring disease. Buckingham: Open University Press; 1995.

14. Bąk-Drabik K, Ziora D. [Influence of socioeconomic status on the quality of life of patients with chronic obstructive pulmonary disease]. Pneumon Alergol Pol. 2010;78:3-13. Polish.

15. Kasibowska-Kuźniar K, Jankowska R, Kuźniar T. [The impact of pulmonary rehabilitation on the quality of life of patients with chronic obstructive pulmonary disease (COPD)]. Wiad Lek. 2007;60:158-64. Polish.

16. Pelham B. Self-investement and self-esteem: evidence for Jamesian model of self-worth. J Pers Soc Psychol. 1995;69:1141-50, https://doi.org/10.1037/0022-3514.69.6.1141.

17. Eiser C, Morse R. Quality of life measures in chronic diseases of childhood. Health Technol Assess. 2001;5:1-162, https://doi.org/10.3310/hta5040.

18. Chan K, Mangione-Smith R, Burwinkle T, Rosen M, Varni J. The PedsQL: reliability and validity of the short form generic core scales and Asthma Module. Med Care. 2005;43:256-65, https://doi.org/10.1097/00005650-200503000-00008.

19. Varni J, Burwinkle T, Jacobs J, Gottschalk M, Kaufman F, Jones K. The PedsQL in type 1 and type 2 diabetes: reliability and validity of the Pediatric Quality of Life Inventory Generic Core Scales and type 1 Diabetes Module. Diabetes Care. 2003;26:631-7, https://doi.org/10.2337/diacare.26.3.631.

20. Varni J, Seid M, Rode C. The PedsQL: measurement model for the pediatric quality of life inventory. Med Care. 1999;37: 126-39, https://doi.org/10.1097/00005650-199902000-00003.

21. Groth A, Groth J. [Quality of life in children with neoplastic diseases]. Pielęg Pol. 2007;1:34-8. Polish.

22. Talecka-Nieczyporuk A, Kaczmarski M. [Research forms of the quality of life of children with allergies]. Klin Pediatr. 2000;8:233-5. Polish. 
23. The KIDSCREEN Group Europe. The KIDSCREEN Questionnaires. Quality of life questionnaires for children and adolescents. Lengerich: Pabst Science Publishers; 2006.

24. Mazur J, Małkowska-Szkutnik A, Dzielska A, Tabak I. [Polish version of the questionnaires to study the quality of life related to the health of children and adolescents (KIDSCREEN)]. Warszawa: Instytut Matki i Dziecka; 2008. Polish.

25. The KIDSCREEN Group Europe. The KIDSCREEN Questionnaires - Quality of life questionnaires for children and adolescents. Lengerich: Pabst Science Publishers; 2011.

26. Karski J. [Health and health promotion]. In: Karski J, Słońska Z, Wasilewski B, editors. [Health promotion]. Warszawa: Sanmedia; 1994. Polish.

27. Mazur J, Małkowska-Szkutnik A. [Health of students in 2018 against the background of the new HBSC research model]. In: Mazur J, editor. [Subjective health assessment]. Warszawa: Instytut Matki i Dziecka; 2018. p. 59-69. Polish.

28. Mazur J, Szumska-Olczak A. [Assessment measures in health promotion programs - selected model approaches]. Med Wieku Rozw. 2000;49:53-66. Polish.

29. Nutbeam D. Evaluating health promotion-progress, problems and solutions. Health Promot Int. 1998;13:27-44.

30. Agathão BT, Reichenheim ME, de Moraes CL. Health-related quality of life of adolescent students. Ciência Saúde Coletiva. 2018;23:659-68, https://doi.org/10.1590/1413-8123201 8232.27572016 .

31. Oleś M. [Youth's quality of life in health and disease]. Lublin: KUL Publishing; 2010. Polish.
32. Bańka A. [Quality of life and quality of development. Social context of gender, activity and family]. In: Bańka A, editor. In: [Psychology of quality of life]. Poznań: Stowarzyszenie Psychologia i Architektura; 2005. p. 11-79. Polish.

33. Burt M. Reasons to invest in adolescents. J Adolesc Health. 2002;31(6 Suppl):136-52, https://doi.org/10.1016/s1054-139x (02)00486-x.

34. Gil-Lacruz M, Gil-Lacruz AI, Gracia-Pérez ML. Healthrelated quality of life in young people: the importance of education. Health Qual Life Results. 2020;18:187, https:// doi.org/10.1186/s12955-020-01446-5.

35. Krawczyńska J, Zięba E, Zięba P, Nowak-Starz G. [Location of health control and health self-assessment of youth from upper secondary schools]. Probl Pielęg. 2014;22:445-52. Polish.

36. Zięba E, Krawczyńska J, Zięba P, Strzelecka A, NowakStarz G. [Well-being and development and health of children and youth]. In: Markocka- Mączka K, Król H, editors. [Determinants of the health quality of girls with menstrual disorders in adolescence from the urban environment compared to healthy peers in the light of the KIDSCREEN - 52 questionnaire]. Lublin: NeuroCentrum Scientific Publisher; 2016. p. 241-50. Polish.

37. Gallego-Méndez J, Perez-Gomez J, Calzada-Rodríguez J, Denche-Zamorano A, Mendoza-Muñoz M, Carlos-Vivas J, et al. Relationship between health-related quality of life and physical activity in children with hyperactivity. Int J Environ Res Public Health. 2020;17:2804, https://doi.org/10.3390/ ijerph17082804.

This work is available in Open Access model and licensed under a Creative Commons Attribution-NonCommercial 3.0 Poland License - http://creativecommons.org/ licenses/by-nc/3.0/pl/deed.en. 